\title{
The effect of intervention using the PRECEDE-PROCEED model based on quality of life in diabetic patients
}

\author{
Farbod Ebadifard Azar ${ }^{1}$, Mahnaz Solhi ${ }^{2}$, Nazila Nejhaddadgar ${ }^{3}$, Firoz Amani $^{4}$
}

${ }^{1}$ Ph.D. Professor, Department of Health Services and Health Education, Faculty of Health, Iran University of Medical Sciences, Tehran, Iran

${ }^{2}$ Ph.D. Assistant Professor, Department of Health Services and Health Education, School of Health, Iran University of Medical Sciences, Tehran, Iran

${ }^{3}$ Ph.D. Candidate in Health Education and Health Promotion, Department of Health Care Services and Health Education, School of Health, International Campus, Iran University of Medical Sciences, Tehran, Iran

${ }^{4}$ Ph.D. Assistant Professor, Department of Epidemiology and Biostatistics, School of Public Health, Ardebil University of Medical Sciences. Ardebil, Iran

\section{Type of article: Original}

\begin{abstract}
Background: Poor quality of life is common among diabetic patients, and educational intervention is one of the most effective strategies to improve the quality of life for chronic patients.

Objectives: To determine the effect of an educational intervention based on PRECEDE-PROCEED in quality of life of diabetic patients, in 2016.

Methods: In this quasi-experimental study, 86 patients referred to diabetic centers of Ardabil participated. We used the components PRECEDE-PROCEED model for planning, implementation and evaluation of the program. Data collection tools were Diabetes Quality of Life questionnaire (DQOL) and a researcher-made questionnaire. Eight training sessions were conducted for the intervention group for self-efficiency, self- management, attitude, knowledge, and enabling reinforcing factors. Quality of life was followed one and three months after intervention. Data were analyzed through SPSS 16 software using descriptive and analytical tests.

Results: The mean age of patients was $55.88( \pm 12.1)$ years. The result showed that before intervention, no significant difference was observed among the mean scores of quality of life, self-management, knowledge, attitude, enabling and reinforcing factors, and self-efficiency in two groups. But one and three months after intervention a significant difference was observed $(\mathrm{p}<0.001)$.

Conclusion: Educational intervention with PRECEDE-PROCEED model improved the diabetic patient's quality of life.

Keywords: PRECEDE-PROCEED model, Diabetes mellitus, Quality of life
\end{abstract}

\section{Introduction}

Non-communicable diseases (NCDs), also known as lifelong diseases have long duration and commonly slow progression. The most important non-communicable diseases are heart diseases, cancers, chronic respiratory diseases and diabetes. Each year, 15 million people die from NCD between the ages of 30 and 69 years; over $80 \%$ of these "premature" deaths occur in low- and middle-income countries (1). Diabetes is a metabolic that involves abundant complications throughout its course, so that it causes severe restriction in a patient's life. This disease is a chronic disease that occurs either when the pancreas does not secrete enough insulin hormones that regulate blood sugar, or when the body cannot use the insulin (2). High-income countries are nearly 4 times more likely to have

\section{Corresponding author:}

Nazila Nejhaddadgar, Department of Health Care Services and Health Education, School of Health, International Campus, Iran University of Medical Sciences, Tehran, Iran.

Tel: +98.9144534682, Email: naziladadgar60@gmail.com

Received: December 02, 2016, Accepted: April 23, 2017, Published: August 2017

iThenticate screening: March 02, 2017, English editing: June 12, 2017, Quality control: June 24, 2017

This article has been reviewed / commented by three experts

(C) 2017 The Authors. This is an open access article under the terms of the Creative Commons Attribution-NonCommercialNoDerivs License, which permits use and distribution in any medium, provided the original work is properly cited, the use is non-commercial and no modifications or adaptations are made. 
NCD services covered by health insurance than low-income countries. In 2012 diabetes was the cause of 1.5 million deaths and high blood glucose was the cause of another 2.2 million deaths (3). This chronic disease is associated with disabilities, such as blindness, amputation and stroke (4). Diabetes complications may lead to deterioration in a patient's quality of life and needs for lifetime care. Researchers emphasize the informed participation of patients on their self-care and improve their quality of life (5). Quality of life (QOL) can be generally defined by how a person determines the value of the various aspects of their life. Valuations of QOL include a person's emotional reaction to various life experiences, their character, sense of life fulfillment and satisfaction, and fulfilment in their achievements at work and in personal relationships (6). According to the WHO, quality of life is defined as a person's perception of their standing in life in the context of culture and the ethical code in which they live in relation to their standards, objectives, aspirations and apprehensions (7). The results of the previous studies have shown that type 2 diabetes is associated with impaired diabetic patients QOL (8, 9). Health education is the foundation of chronic disease care and treatment. The main objective of educational intervention in terms of diabetes is to change patients' lifestyles and improve their QOL (10). Additional efforts are required to design theory -based education interventions aimed at QOL in diabetic patients. At present, one of the most famous and applicable theories is the PRECEDE -PROCEED model (11). Review of the literature has shown the efficiency of the "precede pattern" in predicting the life quality of various groups of people (12). The PRECEDE-PROCEED model can be used to design and evaluate a health promotion plan. The PRECEDE component allows a researcher to work backward from the ultimate goal of the research to create a project to instruct the formation of the educational intervention. PRECEDE and PROCEED are acronyms. PRECEDE stands for Predisposing, Reinforcing, and Enabling Constructs in Educational/Environmental Diagnosis and Evaluation. PROCEED spells out Policy, Regulatory, and Organizational Constructs in Educational and Environmental Development (13). Hosseini and Hazavei, in their studies, have approved efficiency of this model and obtained acceptable educational results (14, 15). Moreover, the PRECEDE-PROCEED model has been recognized as an effective method for creating and providing the phases which are necessary for improving health and life quality. Most studies report worse quality of life for people with diabetes compared to the general population, especially regarding physical functioning and wellbeing. Self-care education, in patients with chronic diseases such as diabetics is the most important item in controlling the improvement of quality of life and preventing complications and the majority of diabetic patients do not have necessary skills to control their disease. So this concept requires further investigation. The present research is aimed to study and determine effects of an educational program according to PRECEDE-PROCEED model on QOL in diabetic patients. The results of this study can be applied and used for designing interventions in order to improve diabetic patients' life quality.

\section{Material and Methods}

In this quasi-experimental study, based on the previous studies and regarding the formula of comparing two independent groups' mean and also regarding the $95 \%$ confidence level and primary error $\alpha=0.05$, the required sample size was determined as including 86 diabetic patients, in each of the control and case group. The sampling was done through the multi-phase random sampling method such that, first, six centers from among diabetic centers were randomly chosen and, then, the random allocation of the centers to the control and case groups was performed. After coordinating with these centers, the files existing in centers were used in order to obtain a list of diabetic patients. In this study, PRECEDE-PROCEED model with nine phases was used as a theoretical frame for educational intervention. There are four planning phases in the PRECEDE-PROCEED planning model, one executive phase, and three evaluation phases. In this context, health behavior is in two separate parts since it is regarded as being determined by both individual and environmental factors. First is the "educational diagnosis" PRECEDE, which stands for predisposing, reinforcing and enabling constructs in educational diagnosis and evaluation. Then there is the "ecological diagnosis" PROCEED, which stands for policy, regulatory, and organizational constructs in educational and environmental development (12). This model has been recommended in increasing quality of life among chronic disease (13). In phases 1 and 2, a social and epidemiological diagnosis through literature review and focus groups was performed. The results revealed that living with diabetes had a negative impact on the diabetic patient's quality of life. During phase 3, on the basis of literature review and focus groups with diabetic patients, it showed that QOL in patients were influenced by their illness, also, patients did not have good self-management, and at this stage, the general and objective goals of the educational program were compiled. In phase 4, a literature review and a number of focus groups determined the predisposing, reinforcing, and enabling factors that might influence QOL in patients. In this study, predisposing factors included self-management, knowledge, attitude, and self-efficacy related to QOL in patients. Enabling factors can be identified as those that assist the progress of the performance of the health action, such as resources, competence and supportive approaches that are vital to conducting behavior (14). In this study, the enabling factors were educational classes, and 
informational resources, from literature and the Internet. The reinforcing factors are comprised of support from family and health workers. In phase 5, human and material resources and practical plans were prepared. In phase 6, the developed education intervention was implemented. In phases 7 to 9 , process, impact, and outcome evaluation were performed. Demographic and PRECEDE-PROCEED model variables were measured using questionnaires. Content validity test was used for validation of the questionnaire by panel session with fifteen experts, and the questions were changed based on the results. Also, face validity was done based on the experts' comments. Content validity index acquired from all the questions in this section was higher than 0.71 and content validity ratio achieved from all of the questions in this section was higher than 0.66 , which was appropriate in accordance with the Lawshe Table (for ten). Reliability of the researcher-made questionnaire was obtained by Cronbach's alpha test. The obtained correlation coefficients for Cronbach's alpha test for all of the questions was higher than 0.81 . The first part of the scales included questions related to demographic characteristics including age, gender, job, level of education, marital status, number of children, household income, frequency of hospitalization with diabetes, BMI, smoking, and family history. The second part of the scales was a DQOL questionnaire with fifteen questions, and the response items to these questions were Likert-type scale, and response categories varied from "Strongly disagree $=0$ " to "Strongly agree $=5$ ". The third part of the scales was predisposing factors (self-management, knowledge, attitude, and self-efficacy), enabling and reinforcing factors. The knowledge of patients was measured using eight questions with scores given in the following way: A response of "yes" to questions was given one score and a response of "No" to questions received no score. The attitude of patients was measured using fourteen questions, the items were measured on Likert-type scale, ranging from "Strongly disagree $=0$ " to "Strongly agree $=5$ ". The enabling factors scale consisted of nine questions (Available resource, educational programs). The reinforcing factors scale consisted of three items, scores were given in the following way: A response of "Yes" to each question was given one score and a response of "No" to questions received no score. In order to calculate the reliability of these questionnaires, the method of test-retest was used during a two-week time span for thirty patients $(\mathrm{r}=0.83)$. Self-management includes sixteen questions about healthy eating, being active, monitoring, taking medication, problem solving, reducing risks. Scoring the questions for self-management were scored on a 4-point Likert scale as $1=$ never $2=$ rarely, $3=$ sometimes, and $4=$ often. The designed educational intervention with PRECEDE-PROCEED model for case group encompassed 45 to 60 minutes per session for 8 weeks. The patients randomized to the control group received routine care provided at a diabetic center. This training was about healthy eating, exercise and medication. Finally, the impact of the educational program on the promotion of the patient's quality of life was measured 4 weeks after the first intervention and outcome of educational intervention was measured 12 weeks after the first intervention. SPSS version 21 (PASW Statistics for Windows, Chicago: SPSS Inc.) was used for data analysis. Continuous variables were expressed as mean $\pm \mathrm{SD}$. The ANOVA and paired t-test were used to determine statistical differences in continuous variables between the two groups. The relation between categorical variables was examined by Chi-square test. We used the linear regression to obtain the relation between all effective variables on QOL in patients. The study was approved by Iran University of Medical Sciences. All ethical issues, informed consent, conflict of interest, and plagiarism have been considered carefully by the authors. The respondents were anonymous and participated willingly in this study.

\section{Results}

A total of 86 diabetic patient participated in this study. The mean age of patients was $55.88 \pm 12.1$ years. The length of time participants had been diagnosed with diabetes averaged $8.5 \pm 4.7$ years and the BMI was $28.7 \pm 41.4$. Most of the participants were overweight or obese $(69.8 \%)$. Of all participants, $9.8 \%$ were currently smoking and $78.3 \%$ reported history of diabetes in their family. The most frequently reported comorbidities were hypertension (61\%) and $12 \%$ of the participants reported a previous heart attack. Most of the patients in this study $(35.7 \%)$ were at the level of guidance schools and $20.2 \%$ were illiterate. Most of the participants had income less than their budget $(52.7 \%)$ (Table 1). In assessment of baseline comparability of intervention and control group there were no significant differences in any of the demographics characteristics, knowledge, attitude, self-efficiency, selfmanagement, enabling and reinforcing factors and quality of life scores between the two groups ( $>0.005)$. But after intervention, there were a significant difference among them. And the mean scores of knowledge, belief, selfefficiency; diabetic self-management, enabling and reinforcing factors and quality of life in the intervention group were significantly higher than the control group (Tables 2, 3). Pearson's correlation coefficients (r) indicated that quality of life was significantly correlated with attitude $(\mathrm{r}=0.2, \mathrm{p}<0.001)$, self-management $(\mathrm{r}=0.665, \mathrm{p}<0.001)$, enabling factors $(\mathrm{r}=-0.8, \mathrm{p}<0.001)$ and self-efficiency $(\mathrm{r}=0.21, \mathrm{p}<0.001)$. A regression model including selfmanagement $(\beta=0.381$, standard error $=0.320, p=0.001)(R 2=0.43, F=4.7, p<0.001)$ significantly predicted the quality of life that explained 0.43 of QOL variances. 
Table 1. Baseline characteristics of patient mean $( \pm \mathrm{SD})$

\begin{tabular}{|c|c|c|c|c|}
\hline \multirow{2}{*}{\multicolumn{2}{|c|}{ Variable }} & \multicolumn{2}{|l|}{ Group } & \multirow[t]{2}{*}{$\mathrm{p}$-value } \\
\hline & & Intervention; $\mathrm{n}(\%)$ & Control; n (\%) & \\
\hline \multirow[t]{2}{*}{ Sex } & Men & $18(41.9)$ & $23(53.5)$ & \multirow[t]{2}{*}{0.53} \\
\hline & Woman & $25(58.1)$ & $20(46.5)$ & \\
\hline \multirow[t]{4}{*}{ Educational level } & Illiterate & $8(18.6)$ & $12(27.9)$ & \multirow[t]{4}{*}{0.68} \\
\hline & Elementary & $15(34.9)$ & $19(44.2)$ & \\
\hline & Guidance & $14(32.6)$ & $10(23.3)$ & \\
\hline & Diploma & $6(14)$ & $2(4.7)$ & \\
\hline \multirow[t]{2}{*}{ Marital status } & Single & $1(2.3)$ & $9(20.9)$ & \multirow[t]{2}{*}{0.79} \\
\hline & Married & $42(97.7)$ & $34(79.1)$ & \\
\hline \multirow[t]{3}{*}{ Income } & More than expenditure & $2(4.7)$ & $7(16.3)$ & \multirow[t]{3}{*}{0.59} \\
\hline & Less than expenditure & $30(69.8)$ & $20(46.5)$ & \\
\hline & Equal to the expenditure & $11(25.6)$ & $16(37.2)$ & \\
\hline Age & Mean \pm SD & $56.65 \pm 10.76$ & $55.09 \pm 13.41$ & 0.66 \\
\hline
\end{tabular}

Table 2. Average responses diabetes quality of life before, 4 and 12 weeks after educational program

\begin{tabular}{|l|l|l|l|l|l|}
\hline \multicolumn{2}{|l|}{ Independent variables } & $\begin{array}{l}\text { Before intervention; } \\
\text { mean (SD) }\end{array}$ & $\begin{array}{l}4 \text { weeks after } \\
\text { intervention; mean } \\
\text { (SD) }\end{array}$ & $\begin{array}{l}12 \text { weeks after } \\
\text { intervention; mean (SD) }\end{array}$ & $\begin{array}{l}\text { p- } \\
\text { value }\end{array}$ \\
\hline $\begin{array}{l}\text { Quality of } \\
\text { life }\end{array}$ & $\begin{array}{l}\text { Intervention } \\
\text { group }\end{array}$ & $44.25(6.89)$ & $54.09(4.57)$ & $47.27(5)$ & 0.001 \\
\cline { 2 - 6 } & Control group & $42(8.33)$ & $42.69(5.3)$ & $42.63(4.3)$ & 0.235 \\
\hline
\end{tabular}

Table 3. Average responses for variables before, 4 and 12 weeks after educational program

\begin{tabular}{|l|l|l|l|l|l|l|l|l|}
\hline Variables & \multicolumn{3}{|l|}{ Intervention group $(\mathrm{n}=43) ;$ mean $( \pm \mathrm{SD})$} & \multicolumn{3}{l|}{ Control group $(\mathrm{n}=43) ;$ mean $( \pm \mathrm{SD})$} \\
\cline { 2 - 10 } & $\begin{array}{l}\text { Before } \\
\text { intervention }\end{array}$ & $\begin{array}{l}4 \text { weeks } \\
\text { after } \\
\text { intervention }\end{array}$ & $\begin{array}{l}\text { 12 weeks } \\
\text { after } \\
\text { intervention }\end{array}$ & $\begin{array}{l}\text { p- } \\
\text { value }\end{array}$ & $\begin{array}{l}\text { Before } \\
\text { intervention }\end{array}$ & $\begin{array}{l}\text { 4 weeks } \\
\text { after } \\
\text { intervention } \\
\text { after } \\
\text { intervention }\end{array}$ & $\begin{array}{l}\text { v- } \\
\text { value }\end{array}$ \\
\hline Knowledge & $3 \pm 1.34$ & $6.04 \pm 1.58$ & $5.09 \pm 1.60$ & $<0.001$ & $3.37 \pm 1.44$ & $3.38 \pm 1.5$ & $3.41 \pm 1.28$ & $>0.001$ \\
\hline Beliefs & $45.34 \pm 11.01$ & $52.41 \pm 6.24$ & $48.18 \pm 7.11$ & $<0.001$ & $43.20 \pm 9.6$ & $44.26 \pm 3.1$ & $43.12 \pm 4$ & $>0.001$ \\
\hline Self-efficacy & $10.76 \pm 4.87$ & $13.65 \pm 3.27$ & $11.60 \pm 2.61$ & $<0.001$ & $10.41 \pm 4.38$ & $10.30 \pm 2.46$ & $10.33 \pm 1.3$ & $>0.001$ \\
\hline $\begin{array}{l}\text { Self- } \\
\text { management }\end{array}$ & $39.25 \pm 9.36$ & $49.27 \pm 6.53$ & $48.93 \pm 5.81$ & $<0.001$ & $40.13 \pm 5.89$ & $40.13 \pm 4.29$ & $40.16 \pm 3.2$ & $>0.001$ \\
\hline $\begin{array}{l}\text { Reinforcing } \\
\text { factors }\end{array}$ & $1.79 \pm 0.98$ & $1.97 \pm 0.85$ & $1.83 \pm 0.75$ & $<0.001$ & $1.58 \pm 0.87$ & $1.59 \pm 0.1$ & $1.59 \pm 0.2$ & $>0.001$ \\
\hline $\begin{array}{l}\text { Enabling } \\
\text { factors }\end{array}$ & $3.90 \pm 1.25$ & $4.60 \pm 1.43$ & $4.11 \pm 1.41$ & $<0.001$ & $3.27 \pm 1.11$ & $3.29 \pm 1.32$ & $3.30 \pm 1.30$ & $>0.001$ \\
\hline
\end{tabular}

\section{Discussion}

The results of this study showed that following intervention, the quality of life and PRECEDE variable significantly increased in the intervention group. The results demonstrated that the quality of life in diabetic patients improved using the PRECEDE-PROCEED model with educational intervention. Furthermore, following the intervention, mean scores of the PRECEDE variable were significantly higher in the case group. Our research revealed that the capabilities of educational intervention with PRECEDE-PROCEED model are little known and require further study. However, our findings are in line with those of Mazloomy (16) who established that implementing intervention based on the PRECEDE model enhanced quality of life in the elderly. Another study showed that the precede-proceed model can be effective in improving the quality of life for heart patients (17). Also, Oruoj reported that the precede-proceed model can be effective for promoting the preventive behaviors for type 2 DM in high-risk individuals (18). In this study, it was established that the intervention group had more self-efficiency after intervention, in comparison to the control group. It can also be said that one of the effective aspects in selfmanagement of chronic patients, particularly diabetes patients, is self-efficacy. Self-efficacy is a basic requirement of this behavior, considering it constitutes the independent part of basic personal skills $(19,20)$ It had a significant impact on performing the behaviors promoting quality of life in diabetic patients; Bernal showed that diabetic patients with low self-management had lower self-efficacy, also, self-efficacy had a relationship with self- 
management in food and insulin use in diabetic patients (21). Given that self-efficacy of patients in the control group was not increased through usual care, more attention to this change in diabetic patients is required. In the PRECEDE model, predisposing factors such as self-efficiency precede behavior and improve the behavior. Therefore, selfefficiency of the participants facilitated adopting ways. Following the intervention, the mean score of selfmanagement significantly increased in the case group compared to the control group. Self-management in chronic disease is recognized as an important component for the control of type 2 diabetes (22). Diabetic self-management is a complex process requiring a certain amount of astuteness and perception, also evaluating signs and symptom and taking action to treat those changes (23). In Ekhtiari's study findings showed that self-management education improves self-care heart failure patients and self-management education could improve patient's quality of life among them (24). Solhi showed that after educational intervention based on PRECEDE, the average score of predisposing factors in the case group, compared to the control group, changed significantly (25). The selfmanagement as predisposing factor is a facilitator for self-care behavior, therefore, self- management is an important factor in promotion of quality of life of chronic patients. Following the intervention, the mean score knowledge in the case group was significantly higher than the control group. It is essential that patients with diabetes have awareness of the signs and symptoms of hyperglycemia and methods that control their condition (26\&27). Low awareness has been consistently associated with lack of control and disease management (28). Otero showed that an educational program increased the knowledge of diabetes of the IG (29). Studies which established group educational programs for chronic patients, using practical teaching activities, such as role play, focus groups, relating stories of experiences and light exercise, also found an increase in understanding and attitude regarding the disease (30) Our study also showed that mean score of enabling and reinforcing factors significantly increased in the intervention group compared to the control group. These findings are in agreement with Solhi (25), Ranjbaran (31) Sabzmakan (32) and Dizaj (33) who reported that implementing intervention using the PRECEDE model could increase enabling and reinforcing factors. In the current study, self-management significantly predicted the quality of life in diabetic patients, self-management of diabetes is closely connected to quality of life in diabetic patients. This participation can succeed only if those with diabetes and their health care providers are informed about taking effective care for the disease (34). Diabetes self-management is a key element in preventing and treating diabetes (35) Safari showed that self-management had a positive direct effect on self-care and quality of life in patients (36), also these findings were in agreement with Sharifirad (37) Hazavehei (38) and Chiang (39). Although this study was on the effectiveness of a PRECEDE-PROCEED model to develop theory-based intervention regarding quality of life in diabetic patients, it had some restrictions. Some patients had no desire to participate in this study although the importance of the study as well as the impact of our programs to improve their quality of life was explained to them.

\section{Conclusions}

The educational intervention based on the PRECEDE-PROCEED model improved diabetic patient's quality of life. The innovation of this study is the approached intervention on the quality of life diabetic patients for the first time.

\section{Acknowledgments:}

This study was part of a Ph.D. approved by the department in number 9522181. This study was approved by the Ethics Committee of Iran University of Medical Sciences (IR.IUMS.REC.1395.221). It is also registered in IRCT and its registration ID is IRCT 9522181. We would like to thank the Deputy of Research of Iran University of Medical Sciences for financial support of this study, and we are also thankful to all participants in this study.

\section{Conflict of Interest:}

There is no conflict of interest to be declared.

Authors' contributions:

All authors contributed to this project and article equally. All authors read and approved the final manuscript.

\section{References:}

1) Lim SS, Vos T, Flaxman AD, Danaei G, Shibuya K, Adair-Rohani H, et al. A comparative risk assessment of burden of disease and injury attributable to 67 risk factors and risk factor clusters in 21 regions, 19902010: a systematic analysis for the Global Burden of Disease Study 2010. The lancet. 2012; 380(9859): 2224-60. doi: 10.1016/S0140-6736(12)61766-8.

2) Assal JP, Groop L. Definition, diagnosis and classification of diabetes mellitus and its complications. World Health Organization. 1999; 1-65. 
3) Wild S, Roglic G, Green A, Sicree R, King H. Global prevalence of diabetes estimates for the year 2000 and projections for 2030. Diabetes care. 2004; 27(5): 1047-53. doi: 10.2337/diacare.27.5.1047. PMID: 15111519 .

4) Leung MW, Yen IH, Minkler M. Community based participatory research: a promising approach for increasing epidemiology's relevance in the 21st century. Int J Epidemiol. 2004; 33(3): 499-506. doi: 10.1093/ije/dyh010. PMID: 15155709.

5) Khunti K, Gray LJ, Skinner T, Carey ME, Realf K, Dallosso H, et al. Effectiveness of a diabetes education and self-management programed (DESMOND) for people with newly diagnosed type 2 diabetes mellitus: three year follow-up of a cluster randomised controlled trial in primary care. BMJ. 2012; 344: e2333. doi: 10.1136/bmj.e2333. PMID: 22539172, PMCID: PMC3339877.

6) Wen J, Shi YK, Li YP, Yuan P, Wang F. Quality of life, physical diseases, and psychological impairment among survivors 3 years after Wenchuan earthquake: a population based survey. PLoS One. 2012; 7(8): e43081. doi: 10.1371/journal.pone.0043081. PMID: 22937014, PMCID: PMC3427990.

7) Brown TM, Cueto M, Fee E. The World Health Organization and the transition from "international" to "global" public health. Am J Public Health. 2006; 96(1): 62-72. doi: 10.2105/AJPH.2004.050831. PMID: 16322464, PMCID: PMC1470434.

8) Stewart AL, Greenfield S, Hays RD, Wells K, Rogers WH, Berry SD, et al. Functional status and wellbeing of patients with chronic conditions: results from the Medical Outcomes Study. JAMA. 1989; 262(7): 907-13. doi: 10.1001/jama.1989.03430070055030. PMID: 2754790.

9) Fukuoka Y, Lindgren TG, Rankin SH, Cooper BA, Carroll DL. Cluster analysis: a useful technique to identify elderly cardiac patients at risk for poor quality of life. Qual Life Res. 2007; 16(10): 1655-63. doi: 10.1007/s11136-007-9272-7. PMID: 17955345.

10) Didehvar M, Zareban I, Jalili Z, Bakhshani NM, Shahrakipoor M, Balouchi A. The Effect of Stress Management Training through PRECEDE-PROCEED Model on Occupational Stress among Nurses and Midwives at Iran Hospital, Iranshahr. J Clin Diagn Res. 2016; 10(10): LC01-LC05. doi: 10.7860/jcdr/2016/22569.8674. PMID: 27891358, PMCID: PMC5121696.

11) Mollaoğlu M, Beyazit E. Influence of diabetic education on patient metabolic control. Appl Nurs Res. 2009; 22(3): 183-90. doi: 10.1016/j.apnr.2007.12.003. PMID: 19616166.

12) Naderi V, Borjali A, Mansobifar M. Researchers believe that stress management skills, is effective on life. J Health Psychol. 2011; 1(2): 13-30.

13) Green LW, Kreuter MW. Health program planning: An educational and ecological approach. McGraw-Hill Companies; 2005.

14) Hosseini F, Farshidi H, Aghamolaei T, Madani A, Ghanbarnejad A. The impact of an educational intervention based on PRECEDE-PROCEED model on lifestyle changes among hypertension patients. Iran J Health Educ Health Promot. 2014; 2(1): 17-27.

15) Hazavei SM, Sabzmakan L, Hasanzadeh A, Rabiei K, Roohafza H. The effects of an educational program based on PRECEDE model on depression levels in patients with coronary artery bypass grafting. ARYA Atheroscler. 2012; 8(1): 36-42. PMID: 23056099, PMCID: PMC3448400.

16) Mazloomymahmoodabad S, Masoudy G, Fallahzadeh H, Jalili Z. Education based on precede-proceed on quality of life in elderly. Glob J Health Sci. 2014; 6(6): 178-84. doi: 10.5539/gjhs.v6n6p178. PMID: 25363108 , PMCID: PMC4825517.

17) Gielen AC, McDonald EM, Gary TL, Bone LR. Using the precede-proceed model to apply health behavior theories. Health behavior and health education: Theory, research, and practice. 2008; 4: 407-29.

18) Oruoji MA, Hashemi J, Hazavehei M, Charkazi A, Javaheri J, Moazeni M. The positive impact of educational intervention program based on PRECEDE model on preventive preventive behaviors to reduce brucellosis in the rural people of Khomein. Journal of Research Development in Nursing \& Midwifery. 2012; 9(1): 51-60.

19) Fertman CI, Allensworth DD. Health promotion programs: from theory to practice. John Wiley \& Sons; 2010.

20) Dehdari T, Heidarnia AR, Ramezankhani A, Sadeghian S, Ghofranipour F, Etemad S. Planning and evaluation of an educational intervention programme to improve life quality in patients after coronary artery bypass graft-surgery according to PRECEDE-PROCEED model. J Birjand Univ Med Sci. 2008; 15(4): 27-37.

21) Bernal H, Woolley S, Schensul JJ, Dickinson JK. Correlates of self-efficacy in diabetes self-care among Hispanic adults with diabetes. Diabetes Educ. 2000; 26(4): 673-80. doi: 10.1177/014572170002600415. PMID: 11212851. 
22) Moshki M, Dehnoalian A, Alami A. Effect of Precede-Proceed Model on Preventive Behaviors for Type 2 Diabetes Mellitus in High-Risk Individuals. Clinical nursing research. 2016; 11(6): 163-8. doi: 1054773815621026.

23) Wu SF, Courtney M, Edwards H, McDowell J, Shortridge - Baggett LM, Chang PJ. Self - efficacy, outcome expectations and self - care behaviour in people with type 2 diabetes in Taiwan. J Clin Nurs. 2007; 16(11c): 250-7. doi: 10.1111/j.1365-2702.2006.01930.x. PMID: 17931318.

24) Soleiman Ekhtiari Y, Shojaeizadeh D, Rahimi Foroushani A, Ghofranipour F, Ahmadi B. The Effect of an Intervention Based on the PRECEDE- PROCEED Model on Preventive Behaviors of Domestic Violence Among Iranian High School Girls. Iran Red Crescent Med J. 2013; 15(1): 21-8. doi: 10.5812/ircmj.3517. PMID: 23486646, PMCID: PMC3589774.

25) Solhi M, Shabani Hamedan M, Salehi M. A PRECEDE-PROCEED based educational intervention in quality of life of women-headed households in Iran. Med J Islam Repub Iran. 2016; 30: 417. PMID: 28210582, PMCID: PMC5307607.

26) Stuifbergen AK, Seraphine A, Roberts G. An explanatory model of health promotion and quality of life in chronic disabling conditions. Nurs Res. 2000; 49(3): 122-9. doi: 10.1097/00006199-200005000-00002. PMID: 10882316.

27) Zhu C, Geng Q, Yang H, Chen L, Fu X, Jiang W. Quality of life in China rural-to-urban female migrant factory workers: a before-and-after study. Health Qual Life Outcomes. 2013; 11: 123. doi: 10.1186/14777525-11-123. PMID: 23875650, PMCID: PMC3725152.

28) Otero LM, Zanetti ML, Ogrizio MD. Knowledge of diabetic patients about their disease before and after implementing a diabetes education program. Rev Lat Am Enfermagem. 2008; 16(2): 231-7. doi: 10.1590/S0104-11692008000200010. PMID: 18506341.

29) Williams MV, Baker DW, Parker RM, Nurss JR. Relationship of functional health literacy to patients' knowledge of their chronic disease: a study of patients with hypertension and diabetes. Arch Intern Med. 1998; 158(2): 166-72. doi: 10.1001/archinte.158.2.166. PMID: 9448555.

30) Ranjbaran S, Dehdari T, Sadeghniiat-Haghighi K, Majdabadi MM. Poor Sleep Quality in Patients after Coronary Artery Bypass Graft Surgery: An Intervention Study Using the PRECEDE-PROCEED Model. J Tehran Heart Cent. 2015; 10(1): 1-8. PMID: 26157457, PMCID: PMC4494514.

31) Sabzmakan L, Hazavehei S, Morowatisharifabad M, Hasanzadeh A, Rabiee K, Sadeqi M. The effects of a PRECEDE-based educational program on depression, general health, and quality of life of coronary artery bypass grafting patients. Asian J Psychiatr. 2010; 3(2): 79-83. doi: 10.1016/j.ajp.2010.04.003. PMID: 23051197.

32) Dizaji MB, Taghdisi MH, Solhi M, Hoseini SM, Shafieyan Z, Qorbani M, et al. Effects of educational intervention based on PRECEDE model on self care behaviors and control in patients with type 2 diabetes in 2012. J Diabetes Metab Disord. 2014; 13(1): 1. doi: 10.1186/2251-6581-13-72. PMID: 25075380, PMCID: PMC4114427.

33) Ishikawa H, Takeuchi T, Yano E. Measuring functional, communicative, and critical health literacy among diabetic patients. Diabetes care. 2008; 31(5): 874-9. doi: 10.2337/dc07-1932. PMID: 18299446.

34) Shumway JM, Harden RM. AMEE Guide No. 25: The assessment of learning outcomes for the competent and reflective physician. Med Teach. 2003; 25(6): 569-84. doi: 10.1080/0142159032000151907. PMID: 15369904.

35) Safari M, Amini N, Eftekhar AH, Mahmoudi M, Sanaeinasab H. Evaluation of an educational intervention based on PRECEDE PROCEED model toward lifestyle improvement among adolescents. Daneshvar med. 2012; 19(98): 1-11.

36) Sharifirad G, Ghaffari M, Zanjani S, Hassanzadeh A. The effectiveness of educational intervention based on PRECEDE the level of stress (stress) seniors attending the eyes of the world centers of Tehran. Health Syst Res. 2012; 7(5).

37) Hazavehei SM, Sharifirad G, Mohabi S. The effect of educational program based on health belief model on diabetic foot care. International Journal of Diabetes in Developing Countries. 2007; 27(1). doi: 10.4103/0973-3930.34753.

38) Chiang LC, Huang JL, Yeh KW, Lu CM. Effects of a Self - Management Asthma Educational Program in Taiwan Based on PRECEDE - PROCEED Model for Parents with Asthmatic Children. J Asthma. 2004; 41(2): 205-15. doi: 10.1081/JAS-120026078. PMID: 15115173. 